of the temperature curve (I779 maximum and 1785 minimum) are precisely where, according to the mean length of the sun-spot period of II'I years, they must be ; that there may, perhaps, be an I years period in the temperature independent of the sun-spot period, and that, in the present case, a displacement which the spot period has experienced is not shared by the temperature period; we have to remember that the correspondence of the temperature changes in $1815-54$, does not merely extend to the average length of the periods, but that all peculiarities and disturbances in the sun-spot curve are, in these 30 or 40 years, reflected in the temperature curve. Further observation is needed to explain this phenomenon. Possibly (the author suggests), we have here the interference of a number of quite independent periodical actions; and (without laying stress on the fact, in default of causal evidence), he notices that the greatest negative anomalies occur, for a considerable time, in a series which progresses by multiples of 9 , and in such a manner that an interval of 27 alternates with one of 18 years. Thus-

$$
\begin{aligned}
& 1740=1767=1785=1812=1830=1857 \\
& +27+18+27 \quad+18+27
\end{aligned}
$$

The first four agree; there is merely the quite isolated cold year 1794 intermediate. Going further, we find divergence; for the table shows a strong negative anomaly about 1836 ; but we have, again, the well. authenticated negative anomaly of $1856-57$ conforming to the rule. Renou has assigned, for the return of the cold winter of south-western Europe, a period of 41 years; the author asks whether the time $27+18=45$ years does not better agree with the phenomenon. On this view, the first winter, reckoning back from 1740 is 1695 , and this is recorded as having been one of excessive cold. Between these two occurs one winter of extraordinary cold, 1709, but it is quite isolated, the neighbouring years having been warm. If we go still further back, the periodicity cannot be ascertained with any certainty. If the rule is correct, and its validity between 1740 and 1857 not a mere accident, i.e. the expression of quite other laws, we have to look for a very cold year in I 875 (being $1857+18$ ).

Dr. Köppen proposes, ir a future communication, to treat of hydro-meteors, and so examine the influence of periodic weather changes (at several years' interval) on some phenomena of organic nature.

\section{LAVOTSIER'S WORK IN THE FOUNDATION OF THE METRIC SYSTEM}

SINCE the publication of the article on the Metric System, in NATURE, vol. viii. p. 386 , my attention has been drawn to some recent information showing the important part taken by the celebrated Lavoisier in the scientific operations for establishing the basis of the metric system of weights and measures in France. Lavoisier's name has hitherto been little noticed amongst those of the men of science who were prominently engaged in this work; but it is now clearly proved that up to the period of his being guillotined on May 8, I794, when he fell a victim to the revolutionary fury during the reign of terror, no one took a more active or serviceable part in the scientific labours for founding the Metric System than Lavoisier.

This information is contained in a "Notice historique sur le Système Metrique," by General Morin, lately published in the "Annales du Conservatoire des Arts et Métiers." It is derived from original documents left by Lavoisier, and now in the possession of the Académie des Sciences. These documents have since been submitted to my inspection by M. Dumas, and full details of them will soon be given to the world in the fifth volume of the works of Lavoisier, which M. Dumas is now completing.
Although Lavoisier's name does not appear in the list of the original Committee of Weights and Measures in France, yet it is shown that he was very actively engagea in making the arrangements for their meetings and in oreparing the minutes of their proceedings, as appears from papers and leiters in his own handwriting. It wes through his personal agency that funds were provided at Paris for continuing the measurement of the arc of the meridian in Spain by Mécha!n. And more particularly, all the actual comparisons for determinin: the lensth and dilatation of the standard measures used by Méchain and Delambre for measuring the basis, and known as the liègles de Borda, were made, not by Borda, but by Lavoisier. The subsequent computations only were made by Borda. Lalande has expressly stated that the work of preparing them was executed by Lavoisier and Borda, but that the construction of the measures of platinum and brass, forming metallic thermometers, and of the comparing apparatus used, was carried out under Lavoisier's directions. The published report upon the construction and verification of these measures in 1792 is contained in the "Base du Systeme Metrique," vol. iii. p. 313. It was drawn up by Borda, but Lavoisier's name is not mentioned in it.

Another very important part of the work, the determination of the weight of a cubic decimetre of water, was carried out, in the first instance, chiefly by Lavoisier. This branch of the operation had been specially entrusted by the Committee to Lavoisier and Haüy. The necessary apparatus was constructed under Lavoisier's directions, and all the requisite measurements and weighings of the cylinder were made by Lavoisier and Haiiy. Hitherto few details of the actual processes of this scientific determination have been given to the public, and the whole credit of determining the weight of a cubic decimetre of water, upon which the kilogram, the unit of metric weight, was based, has been attributed to Lefèvre-Gineau, to whom, in conjunction with Fabbroni, the work was entrusted after Lavoisier's death. In point of fact, Lefèvre-Gineau appears to have repeated, in the winter of 1798-9, all the observations made by Lavoisier and Haüy five years before, using the same instruments and obtain. ing nearly similar results.

The facts are stated as follows by Bugge, the Danish member of the Commission, in the thirtieth of his letters describing his visit to Paris, and published in 1800 :-

"The final results of the labours of this special commission, consisting of Lefevre-Gineau and Fabbroni, to whom Van Swinden and Trallès were afterwards joined), was that the true kilogram, the weight of a cubic decimetre of water at its maximum density, or at $4^{\circ} \mathrm{C}$., was 18,827 French grains of the old French pound, poids de marc.

"By the laws of August $\mathrm{r}, 1763$, and April 7, 1795, the kilogram is determined to be I 88 a I grains of the old French pound, poids de mar, in accordance with the experiments of Lavoisier and Hauiy. This determinationi was adopted by the Chieî Office of Weights and Measures in France, and the Standards have been hitherto made for the Departments accordingly. So that there now exist two kinds of kilograms, the legal or provisional, and the scientific or true kilogram. The difference between them is fourteen old French grains."

The difference is partly attributable to Lavoisier's determination having been made at the temperature of melting ice, instead of that of the maximum density of water adopted for Lefevre-Gineau's determination. The unit of Metric weight, the Kilogramme des Archives, appears to have been based on the later observations of Lefevre-Gineau, and to have been legalised by the law of Dec. 9, 1799, after Bugge's letter was written.

H. W. ChIShoLM 